Review Article

\title{
Investigation of the Dynamic Performance of a Large-Span Suspension Bridge Influenced by Scouring Based on Vehicle-Bridge Coupled Vibration
}

\author{
Qingfei Gao ${ }^{(D)},{ }^{1}$ Biao Wu $\left(\mathbb{D},{ }^{1}\right.$ Renzhi Wang, ${ }^{1}$ Jiaqiang Zhang, \\ Binqiang Guo, ${ }^{2}$ and Jun $\mathrm{Li} \mathbb{( i )}^{3}$ \\ ${ }^{1}$ School of Transportation Science and Engineering, Harbin Institute of Technology, Harbin, Heilongjiang 150090, China \\ ${ }^{2}$ Zhejiang Provincial Institute of Communications Planning, Design \& Research, Hangzhou 310000, China \\ ${ }^{3}$ Department of Municipal and Environmental Engineering, Heilongjiang Institute of Construction Technology, Harbin, \\ Heilongjiang 150025, China
}

Correspondence should be addressed to Qingfei Gao; gaoqingfei@hit.edu.cn

Received 7 October 2020; Revised 25 October 2020; Accepted 29 October 2020; Published 12 November 2020

Academic Editor: Min Luo

Copyright (C) 2020 Qingfei Gao et al. This is an open access article distributed under the Creative Commons Attribution License, which permits unrestricted use, distribution, and reproduction in any medium, provided the original work is properly cited.

To study the damage of bridge pile foundations caused by scouring, two damage mechanisms of scouring are proposed in this paper. Considering the vehicle-bridge coupled vibration in terms of two aspects of the scouring depth and erosion depth, the vertical and transversal dynamic characteristics and dynamic responses of the bridge are studied under different cases for the most sensitive vehicle speed. The dynamic characteristics include the 1st and 2nd vibration modes of the vertical and transversal directions of the bridge. The dynamic responses include the vertical and transversal dynamic load allowances and acceleration of the bridge. The souring depth is more sensitive than the erosion depth, and the $2^{\text {nd }}$ vertical mode is most substantially influenced by scouring and erosion. Because of the small value of the natural frequency of the vertical vibration modes, the transversal vibration modes may be more convenient to obtain. The study of the dynamic responses shows that the scouring depth can be represented by the dynamic load allowance in the middle of the span's section and the erosion depth can be characterized by the dynamic load allowance at the quarter location of the span's section.

\section{Introduction}

Bridges are traffic structures that are used to cross obstacles such as rivers and ravines. They play a large role in our social life and economic construction. In recent years, bridge engineering has achieved rapid development for road and railway transportation applications [1]. Among them, more than 100 large bridges have been built on the Yangtze River alone. For the construction of crossriver and cross-sea bridges, the overall trend is that as the scale increases, the structure becomes increasingly complex [2] and the construction standards increase. At the same time, higher requirements are put forward for the bearing capacity and stability of the foundation. Such improved standards are undoubtedly a good choice. However, a pile foundation in deep water not only experiences more complicated forces but also faces many influencing factors, including hydrology, meteorology, and environmental. Among them, water erosion has a significant impact on the pile foundation.

Scouring is the result of the erosive action of flowing water, excavating and carrying away material from the bed and banks of streams and from around the piers and abutments of bridges [3]. For a large number of bridges that cross rivers, it is easier to find defects in the upper structure, but the foundation scour is relatively hidden, which has become a key mode for the safety of the full bridge structure; this problem will become more prominent as the service life of a bridge increases [4].

In recent years, global climate warming has caused frequent flooding of bridges [5]. In 2017, 1764 bridges were damaged in mainland China, with a cumulative length of 
more than $45,000 \mathrm{~m}$; in 2018, in Shandong alone, 1133 bridges were destroyed by rain and floods; in the same year, a flood discharge of a dammed lake in Ganzi Prefecture, Sichuan Province, occurred where more than 20 bridges along the route were destroyed by water. As of 2019, the total number of highway bridges in China is close to 1 million. However, many newly built bridges have experienced serious damage or even failures in less than 10 years of service. Among them, hydrological effects are the primary cause of the failure of bridge structural functions and safety performance. Bridge erosion is the most important manifestation of hydrological effects. Most bridge destruction and collapse accidents at home and abroad are caused by water erosion. After the Zhengzhou Yellow River Bridge experienced a flood peak in 1956, the maximum scour depth of the No. 7 pier reached $14 \mathrm{~m}$, causing the pier of the bridge to be severely tilted, and it was finally washed out by the Yellow River in 1958. A bridge was damaged by the catastrophic flood in Hebei Province in 1963. In 2002, the Bahe River in Xi'an destroyed five bridges. The old Qin Bridge in Shangluo, Shaanxi Province, was washed out in 2008 due to perennial water erosion and continuous rainfall. The wooden foundation of the bridge was exposed, and the operational safety of the bridge was seriously reduced. The foundations of the Qilihe Bridge in Lu'an, Anhui Province, and the Longhai Railway Bridge in Xianyang are also exposed due to water erosion, which seriously affects the bearing performance of the foundation. Foreign bridge foundations also have the abovementioned problems [6]. In 2009, a railway bridge in Dublin, Ireland, collapsed due to water scouring the foundation, causing great property losses; in 2010, the Norfolk Elkhorn River Railway Bridge in the United States was destroyed by floods; and in 2012 in Utah, the United States, a certain bridge in Montezuma was severely scoured by water. According to the previous survey data, the average annual number of water-damaged bridges in 14 provinces and cities in our country is more than 100 , or even more than 500, far exceeding other factors. The United States has long regarded water damage as the main cause of bridge collapse (the average annual probability is approximately 1/5000) [3]. According to statistics from 1989 to 2000 in the United States and from 1987 to 2011 in the state of New York, the proportion of bridges destroyed by water was as high as $52.7 \%$; the number of structures experiencing water damage in the 823 collapsed bridges was 6 times that of overload and 20 times that of earthquakes [7]. Wardhana and Hadipriono [7] studied over 500 instances of failure of bridge structures in the USA between 1989 and 2000. They found that more than $50 \%$ of cases of bridge failure were attributed to scour due to floods and other hydraulic factors. In all 503 failure bridges, the cases related to flood and scour were 165 and 78 cases, respectively. Lagasse et al. reported that approximately $60 \%$ of all bridge failures are caused by scouring [8]. Some photos are shown in Figure 1.

Taking into account the many uncertain factors of a substructure, bridge engineers have provided a large margin during the design and construction period. However, as the service life increases, it is inevitable that the strength and rigidity of the bridge will decrease due to the erosion of the foundation and further lead to a decrease in safety. For this reason, it is necessary to grasp the technical status and carrying capacity of the bridge in a timely manner during the maintenance process [9]. The code stipulates that, for severely scoured river sections, the impact of scouring on piers and foundations should be considered when checking the bridge, the foundation and riverbed paving conditions should be checked in detail, and the underwater part can be checked through related auxiliary means (underwater cameras, underwater corrosion potentiometer, etc.). Obviously, because of the difficulty in its operation, these auxiliary methods are rarely used in actual situations, laying a great safety hazard for the substructure.

In short, most bridge foundations experience different degrees of scouring and foundation scouring occurs underwater, which has a high degree of concealment and substantially threatens the safety of the bridge structure. Once damaged, the repair cost of a bridge is very large. $\mathrm{Li}$ et al. organized the major problems experienced by marine bridges in terms of wave force action and foundation scour and proposed that marine bridges should be developed using high-precision prediction methods, environmental prediction and prewarning systems, research on the multifactor coupling effect of the environment, scouring numerical simulation technology, and wave current force calculation methods [10]. The overall response of a bridge to static and dynamic loads is influenced by the soil-foundation-structure interaction $[11,12]$. Prendergast et al. presented a vehiclebridge-soil dynamic interaction (VBSDI) model that can be used to simulate the effect of scouring on an integral bridge [13]. Based on the theory of modal parameters and the test on a simply supported bridge, the relationship of the depth and dynamic characteristics with the response of the bridge under instant impulse excitation was discussed [14]. Wen et al. proposed a theory of analyzing the bridge scour condition by tracing the dynamic performance of bridges [15]. Catbas et al. investigated the modal flexibility-based deflection and curvature for damage detection [16]. Zhang et al. identified the scour depths of bridges under conditions of ambient excitation through the integrative application of the Eigensystem realization algorithm (ERA) and the support vector machine (SVM) method [17]. The scour geometry is strongly influenced by the bridge pier shape [18]. In addition, the problem of flood-induced scouring on masonry arch bridges was investigated through the analysis of a real case study [19]. Obviously, there are a large number of scouring results. However, most of them focused on the pile foundation itself or small-span bridges. There is less research about the influence of scouring on the dynamic performance of large-span suspension bridges.

In this paper, based on vehicle-bridge coupled vibration, the dynamic performance of a large-span suspension bridge influenced by scouring is numerically investigated in detail.

\section{Bridge Description}

The Qipanzhou Yangtze River Highway Bridge is located in Hubei Province. This bridge is one of the main channels of the Yangtze River planned by the state and an important 

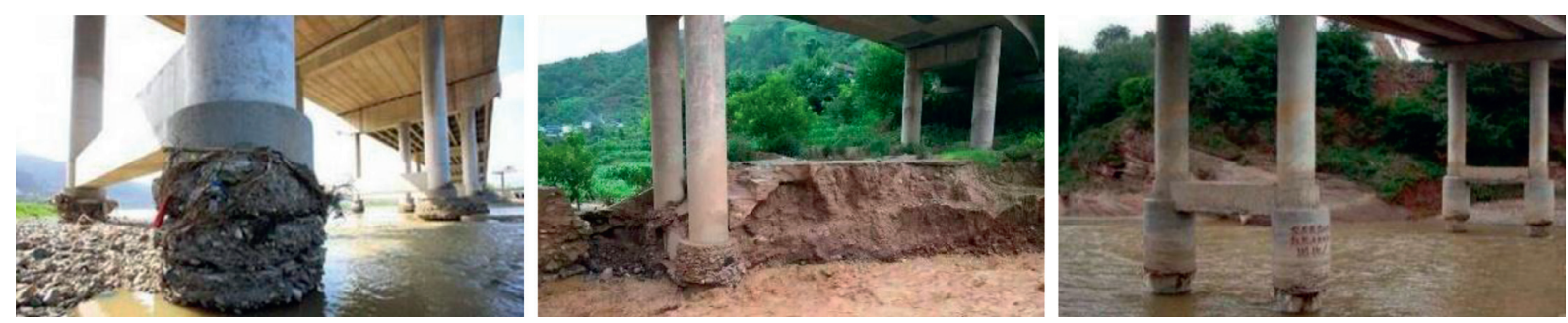

FIgURe 1: Photos of bridge scouring.

bridge across the Yangtze River for the Wuhan City Ring Highway. It is a suspension bridge with one main span and two side spans. The length of the main span is $1038 \mathrm{~m}$. There are 126 suspenders (63 suspenders on every side), and the space between two suspenders is $16 \mathrm{~m}$. A pile foundation is adopted in this bridge. There are 16 piles under every tower. The elevation view of the suspension bridge can be seen in Figure 2.

The basic parameters of the materials used in the bridge are shown in Table 1.

\section{Numerical Model}

For the bridge pile foundation under the action of water scouring, the soil around the pile is constantly being emptied in the vortex formed by the water flow. This results in scouring pits around the pile foundation, and scouring leads to soil loss around the pile and obvious settlement of the pile foundation under the action of vertical load. The horizontal displacement of the pile foundation under the horizontal load increases due to the decrease in the soil resistance.

3.1. Vehicle-Bridge Coupled Vibration. The moving vehicle load is one of the main loads during the operation of the highway bridge. When a vehicle traverses the bridge at a certain speed, the bridge will vibrate under the excitation of the vehicle. In turn, the vibration of the bridge is also a form of excitation for the vehicle. There are mutual influences between vehicles and bridges, and the resulting vibration is called the vehicle-bridge coupled vibration [20].

The vibration equation of the bridge structure can be obtained from the structural dynamics, which is shown in the following equation:

$$
\left[M_{b}\right]\left\{\ddot{U}_{b}\right\}+\left[C_{b}\right]\left\{\dot{U}_{b}\right\}+\left[K_{b}\right]\left\{U_{b}\right\}=\left\{F_{b}\right\},
$$

where $\left\{F_{b}\right\}$ represents the force acting on the bridge, which is caused by moving vehicles, $\left[M_{b}\right]$ represents the mass matrix of the bridge, $\left[C_{b}\right]$ represents the damping matrix of the bridge, and $\left[K_{b}\right]$ represents the stiffness matrix of the bridge. In addition, $\left\{U_{b}\right\}$ is the vibration displacement of the bridge, $\left\{\dot{U}_{b}\right\}$ is the vibration velocity of the bridge, and $\left\{\ddot{U}_{b}\right\}$ is the vibration acceleration of the bridge.

The dynamic equations of the vehicle can be written as

$$
\left[M_{V}\right]\left\{\ddot{Z}_{V}\right\}+\left[C_{V}\right]\left\{\dot{Z}_{V}\right\}+\left[K_{V}\right]\left\{Z_{V}\right\}=\left\{F_{V}\right\},
$$

where $\left\{F_{V}\right\}$ is the load vector induced by the bridge and $\left[M_{V}\right],\left[C_{V}\right]$, and $\left[K_{V}\right]$ are the mass matrix, damping matrix, and stiffness matrix of the vehicle, respectively. Furthermore, $\left\{Z_{V}\right\}$ is the displacement of the vehicle, the first derivative of the displacement is the vibration velocity, and the second derivative of the displacement is the vibration acceleration.

The three-axle vehicle model is adopted in this research (Figure 3). The details of the vehicle model are listed in Table 2 [21].

3.2. Bridge Damage due to Scouring. Scouring will have two effects on the bridge. On the one hand, the water flow will bring up sediment near the bridge piers, form scouring pits, reduce the foundation depth, and reduce the strength and rigidity of the structure. On the other hand, the water flow will carry riverbed sediments to scour the exposed pile, weaken the mechanical properties of the pile, and even completely detach the pile's concrete protective layer, which could lead to steel bar erosion and structural failure.

Among these two aspects, the impact of the scour depth on the bridge structure has been the most studied research topic. When the flood comes, the surging river will erode the riverbed near the piers, increasing the scouring depth and causing changes in the foundation boundary conditions, which can change the dynamic characteristics and dynamic performance of the structure. After a flood, the velocity of the water will decrease and the sediment among the water fills the scouring pit, which will partially restore the original soil depth and mechanical properties around the pile. Therefore, the scouring depth only transiently affects the dynamic characteristics and performance of the structure. However, the more important interfering factor of the dynamic characteristics and performance is the erosion of the cross section.

In addition to changing the height and depth of the soil around the pile, souring will weaken and erode the cross section of the bridge foundation structure. In the design, a larger part of the bridge's basic structure is buried in the soil and is not subject to impact and erosion due to water. However, the water flow can directly erode the bridge foundation structure above the scouring depth. If the scouring depth is high enough, then it is easy for the bridge foundation structure to be quickly eroded by the sediment among the water flow. This would make the concrete protective layer and the steel bars erode more easily. Unlike the change in the scouring depth, the weakened mechanical properties of the foundation structure cannot be restored after the sediment fills back to the pile pit. Therefore, the 


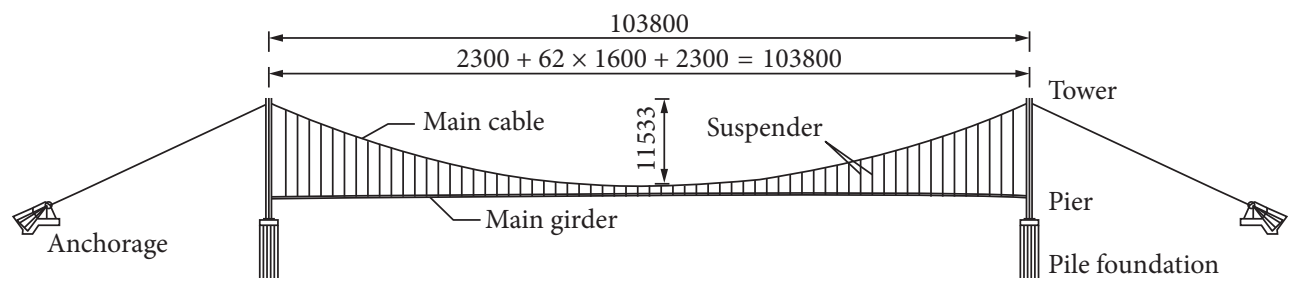

Figure 2: Elevation view of the suspension bridge (unit: $\mathrm{cm}$ ).

TABLE 1: The basic information of the materials.

\begin{tabular}{lcccc}
\hline Materials & Young's modulus $(\mathrm{MPa})$ & Poisson's ratio & Unit weight $\left(\mathrm{kN} / \mathrm{m}^{3}\right)$ & Components \\
\hline Concrete C50 & $3.45 \times 10^{4}$ & 0.2 & 26 & Towers \\
Concrete C30 & $3.00 \times 10^{4}$ & 0.2 & 26 & Pile foundation \\
Steel Q345qD & $2.06 \times 10^{5}$ & 0.3 & 78.5 & Main girder \\
Steel wire & $1.95 \times 10^{5}$ & 0.3 & 78.5 & Main cable and suspenders \\
\hline
\end{tabular}
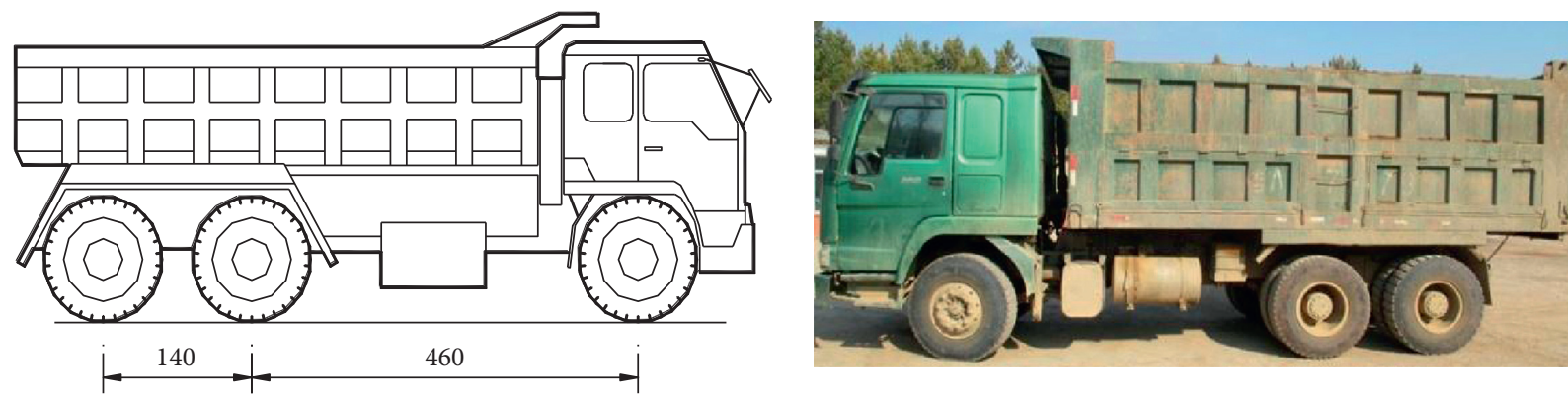

Figure 3: Vehicle diagram (unit: $\mathrm{cm}$ ).

TABle 2: Parameters of the three-axle loading truck.

\begin{tabular}{lc}
\hline Parameters & Value \\
\hline Mass of the truck body & $51800 \mathrm{~kg}$ \\
Mass of the front wheel & $400 \mathrm{~kg}$ \\
Mass of the middle/rear wheel & $600 \mathrm{~kg}$ \\
Pitching moment of inertia & $40000 \mathrm{~kg} \cdot \mathrm{m}[2]$ \\
Rolling moment of inertia & $10000 \mathrm{~kg} \cdot \mathrm{m} \mathrm{[2]}$ \\
Distance (front axle to center) & $4.60 \mathrm{~m}$ \\
Distance (middle axle to center) & $0.36 \mathrm{~m}$ \\
Distance (middle to rear axle) & $1.40 \mathrm{~m}$ \\
Wheel base & $1.80 \mathrm{~m}$ \\
Upper stiffness (front axle) & $1200 \mathrm{kN} \cdot \mathrm{m}^{-1}$ \\
Upper stiffness (middle/rear axle) & $2400 \mathrm{kN} \cdot \mathrm{m}^{-1}$ \\
Upper damping (front axle) & $5 \mathrm{kN} \cdot \mathrm{s} \cdot \mathrm{m}^{-1}$ \\
Upper damping (middle/rear axle) & $10 \mathrm{kN} \cdot \mathrm{s} \cdot \mathrm{m}^{-1}$ \\
Lower stiffness (front axle) & $2400 \mathrm{kN} \cdot \mathrm{m}^{-1}$ \\
Lower stiffness (middle/rear axle) & $4800 \mathrm{kN} \cdot \mathrm{m}^{-1}$ \\
Lower damping (front axle) & $6 \mathrm{kN} \cdot \mathrm{s} \cdot \mathrm{m}^{-1}$ \\
Lower damping (middle/rear axle) & $12 \mathrm{kN} \cdot \mathrm{s} \cdot \mathrm{m}^{-1}$ \\
\hline
\end{tabular}

dynamic characteristics and performance of the bridge structure caused by the weakening of the cross section are permanent and irreversible.

This paper uses ANSYS Parametric Design Language for coding. The bridge structure shown in Section 2 and the vehicle model shown in Section 3.1 are used to simulate different erosion depths and different pile foundation cross- section weakening scenarios. The bridge has two piers, and under each pier cap is a pile group composed of 16 piles. The pile group consists of 4 rows, composed of 4 piles in a row, and the radius of every pile is $1.25 \mathrm{~m}$. The length of the pile under the ground is $70 \mathrm{~m}$.

In the simulation, the change in the soil height around the pile due to scouring is considered to cause the pile foundation to lose its connection with the soil, which releases the constraint of the pile foundation within the scour depth. In the simulation coding, the scouring depth is from $0 \mathrm{~m}$ to $20 \mathrm{~m}$ with 11 working conditions for every $2 \mathrm{~m}$ of scouring depth. The dynamic characteristics and performance analysis are carried out for each scouring depth condition. The cross-section erosion only influences the first row of piles facing the water within a $5 \mathrm{~m}$ scouring depth. The simulation set the erosion depth from $0 \mathrm{~m}$ to $0.5 \mathrm{~m}$ with 11 conditions for every $0.05 \mathrm{~m}$. The dynamic characteristics and performance should also be analyzed as in the scouring depth analysis. A schematic diagram of the erosion depth conditions is shown in Figure 4.

\section{Dynamic Performance of the Bridge}

4.1. Dynamic Characteristics. In this paper, we extract the vertical and transversal vibration modes before the bridge was scoured by using ANSYS software to build the model of the bridge. The result is shown in Figure 5. 


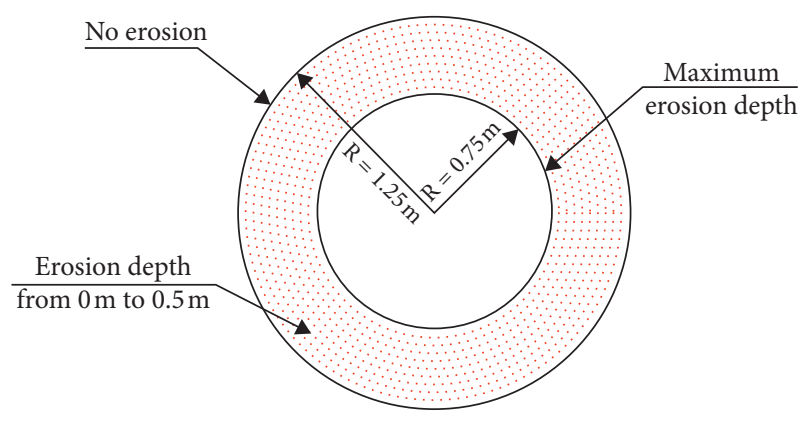

FIGURE 4: Souring depth.

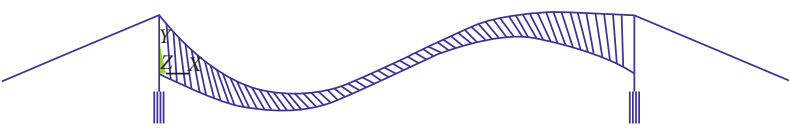

(a)

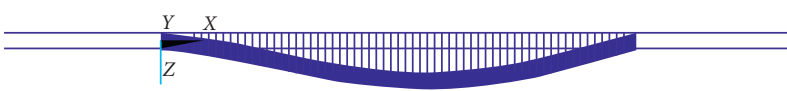

(c)

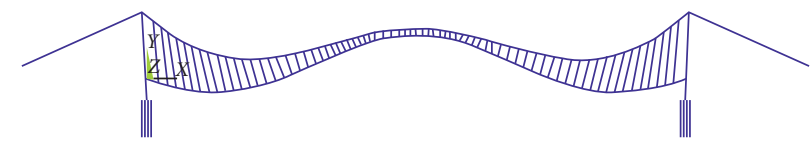

(b)

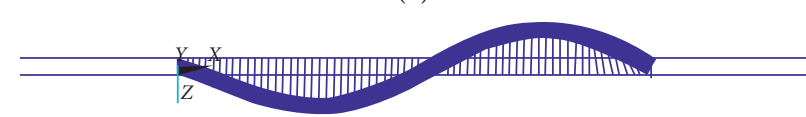

(d)

FIgURe 5: Vibration modes. (a) 1st vertical vibration modes; (b) 2nd vertical vibration modes; (c) 1st transversal vibration modes; (d) 2nd transversal vibration modes.

TABle 3: Dynamic characteristics due to the scouring depth.

\begin{tabular}{|c|c|c|c|c|}
\hline \multirow{2}{*}{ Scouring depth (m) } & \multicolumn{2}{|c|}{ Vertical vibration modes $(\mathrm{Hz})$} & \multicolumn{2}{|c|}{ Transversal vibration modes $(\mathrm{Hz})$} \\
\hline & 1st mode & 2nd mode & 1st mode & 2nd mode \\
\hline 0 & 0.029654 & 0.058678 & 0.104917 & 0.339477 \\
\hline 2 & 0.029653 & 0.056290 & 0.103809 & 0.335965 \\
\hline 4 & 0.029651 & 0.051115 & 0.102341 & 0.331054 \\
\hline 6 & 0.029648 & 0.046503 & 0.101255 & 0.327296 \\
\hline 8 & 0.029646 & 0.042715 & 0.100334 & 0.324057 \\
\hline 10 & 0.029643 & 0.039613 & 0.099494 & 0.321069 \\
\hline 12 & 0.029640 & 0.037038 & 0.098694 & 0.318182 \\
\hline 14 & 0.029637 & 0.034863 & 0.097913 & 0.315290 \\
\hline 16 & 0.029634 & 0.032997 & 0.097137 & 0.312308 \\
\hline 18 & 0.029630 & 0.031376 & 0.096360 & 0.309146 \\
\hline 20 & 0.029626 & 0.029951 & 0.095578 & 0.305705 \\
\hline
\end{tabular}

This paper simulates the effect of bridge scouring by removing the constraint conditions at each single pile node. Each case needs to release the constraint conditions at 128 nodes. A total of 11 ANSYS models need to be built. The 1st and 2 nd modes of the vertical and transversal vibration modes are shown in Table 3 and Figure 6.

From Table 3 and Figure 6, it can be observed that the vertical and transversal vibration frequencies gradually decrease with increasing scouring depth.

The change rate is introduced for additional clarity. The change rate is the relative proportion of the change compared to the good condition. The results are shown in Figure 7.

It can be seen from Figure 7 that the 2 nd mode of the vertical vibration modes changed obviously by the souring depth and the 1st mode of the vertical vibration modes was almost not influenced by the scouring depth. In addition, the 1st mode and the 2 nd mode of the transversal vibration modes changed almost synchronously. Although the 2nd mode of the vertical vibration modes was more sensitive, its natural frequency was very small, which is not easy to obtain on site. By comparing the 1st of the vertical vibration modes with the 1 st of transversal vibration modes, it can be found that the scouring depth has a more substantial influence on the transversal vibration.

To consider the effect of erosion depth, we suppose the scouring depth is 5 meters and simulate the effect of erosion depth by changing the section characteristics of a single pile on one side. The 1st and 2nd modes of the vertical and transversal vibration modes are shown in Table 4 and Figure 8 .

From Table 4 and Figure 8, it can be observed that the vertical and transversal vibration frequencies gradually decrease with increasing erosion depth. The results of the change rate are shown in Figure 9. 


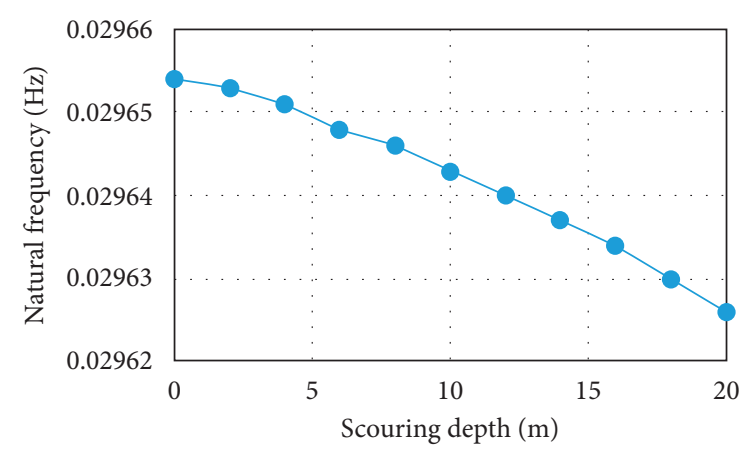

(a)

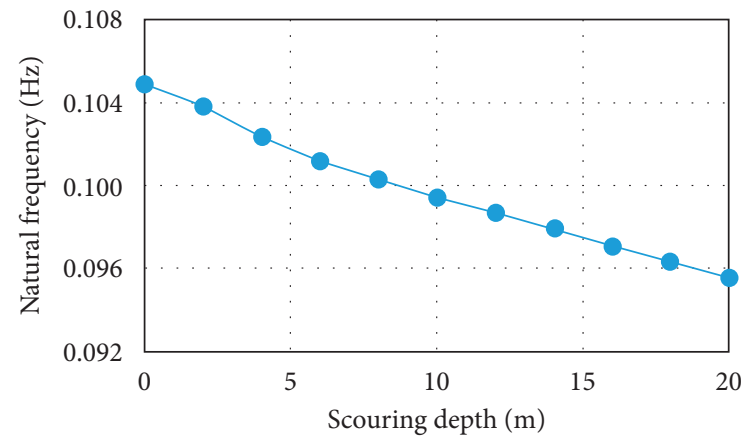

(c)

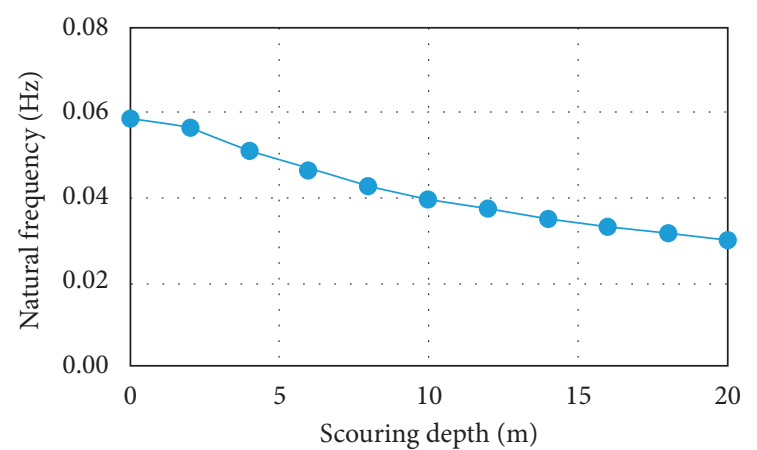

(b)

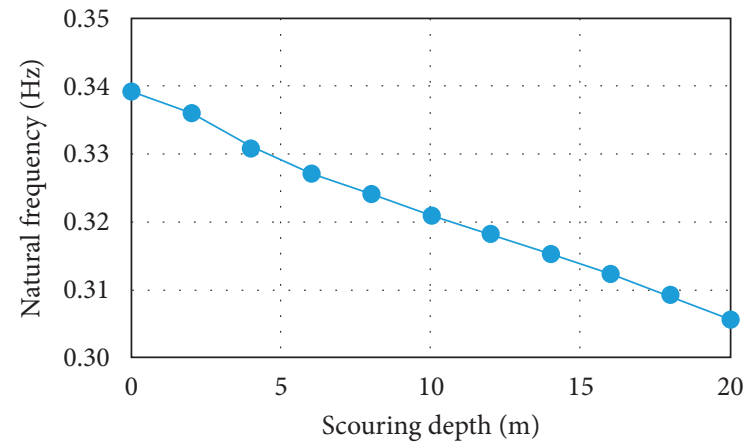

(d)

Figure 6: Dynamic characteristics due to the scouring depth. (a) 1st mode of the vertical vibration modes; (b) 2nd mode of the vertical vibration modes; (c) 1st mode of the transversal vibration modes; (d) 2nd mode of the transversal vibration modes.

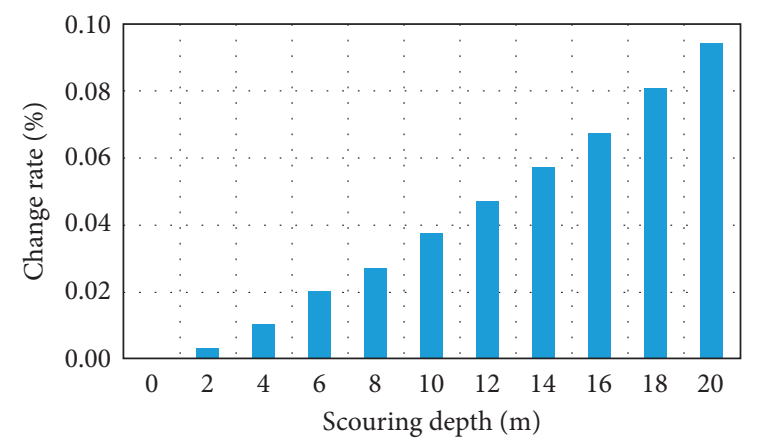

(a)

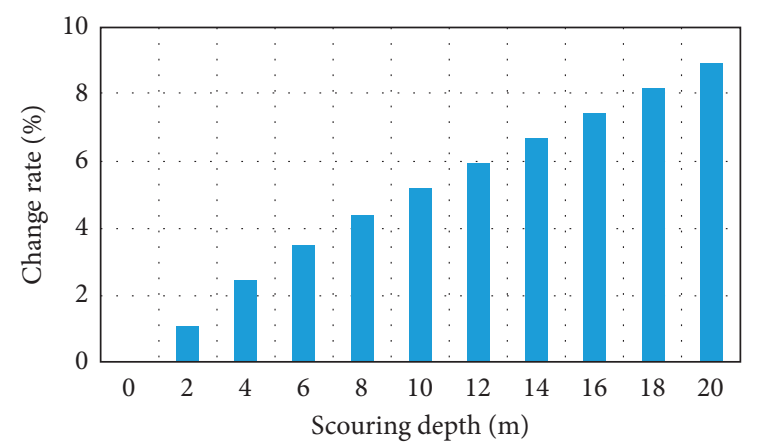

(c)

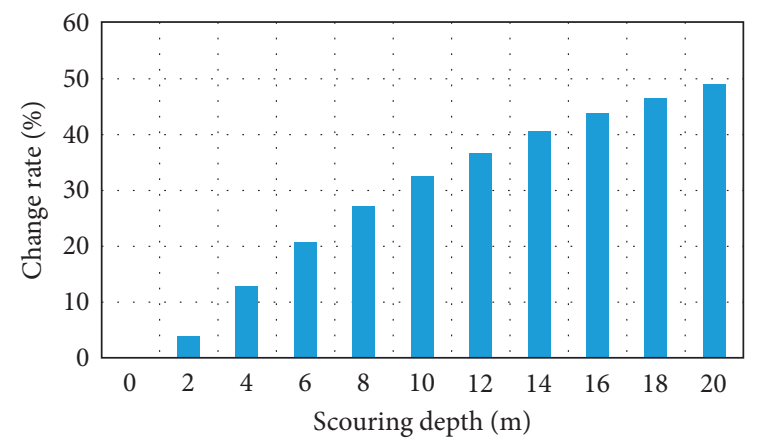

(b)

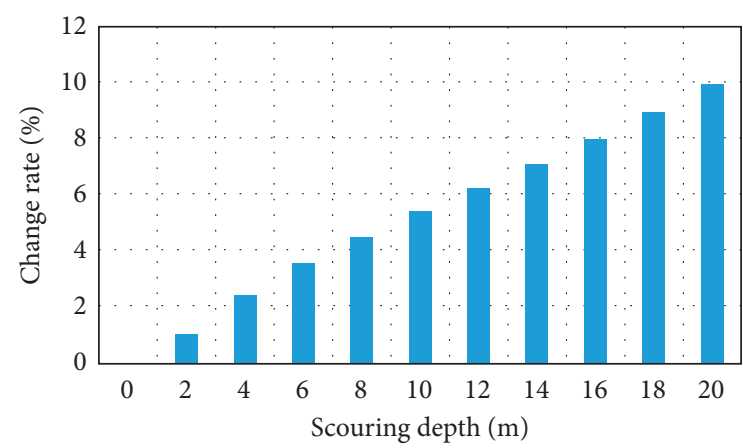

(d)

FIGURE 7: Change rate of the dynamic characteristics due to the scouring depth. (a) 1st mode of the vertical vibration modes; (b) 2nd mode of the vertical vibration modes; (c) 1st mode of the transversal vibration modes; (d) 2nd mode of the transversal vibration modes. 
TABle 4: Dynamic characteristics due to the erosion depth.

\begin{tabular}{|c|c|c|c|c|}
\hline \multirow{2}{*}{ Erosion depth $(\mathrm{m})$} & \multicolumn{2}{|c|}{ Vertical vibration modes $(\mathrm{Hz})$} & \multicolumn{2}{|c|}{ Transversal vibration modes $(\mathrm{Hz})$} \\
\hline & 1st mode & 2nd mode & 1st mode & 2nd mode \\
\hline 0.00 & 0.029653 & 0.055885 & 0.103040 & 0.334576 \\
\hline 0.05 & 0.029653 & 0.055527 & 0.102807 & 0.334096 \\
\hline 0.10 & 0.029652 & 0.055152 & 0.102556 & 0.333608 \\
\hline 0.15 & 0.029652 & 0.054765 & 0.102289 & 0.333119 \\
\hline 0.20 & 0.029652 & 0.054371 & 0.102007 & 0.332634 \\
\hline 0.25 & 0.029653 & 0.053977 & 0.101714 & 0.332159 \\
\hline 0.30 & 0.029652 & 0.053590 & 0.101410 & 0.331700 \\
\hline 0.35 & 0.029652 & 0.053217 & 0.101110 & 0.331260 \\
\hline 0.40 & 0.029651 & 0.052863 & 0.100800 & 0.330840 \\
\hline 0.45 & 0.029651 & 0.052537 & 0.100510 & 0.330450 \\
\hline 0.50 & 0.029651 & 0.052241 & 0.100230 & 0.330090 \\
\hline
\end{tabular}

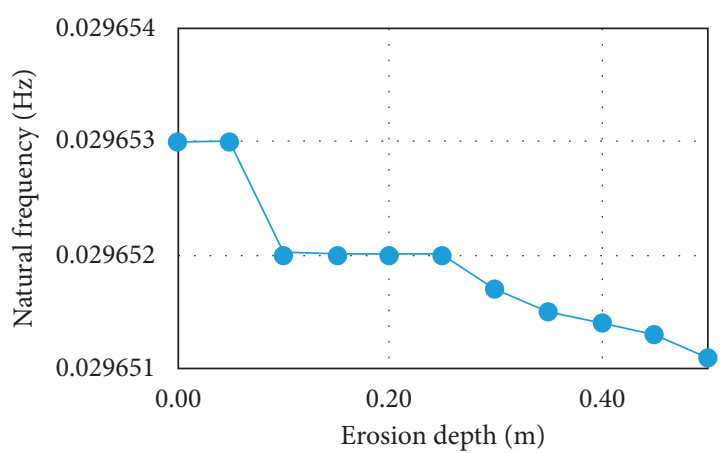

(a)

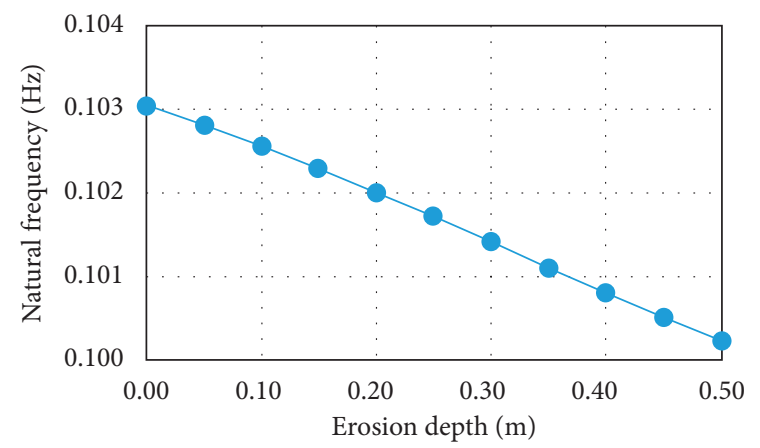

(c)

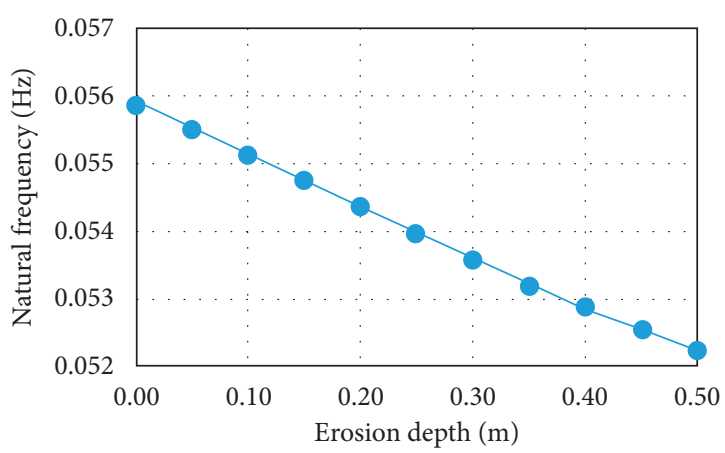

(b)

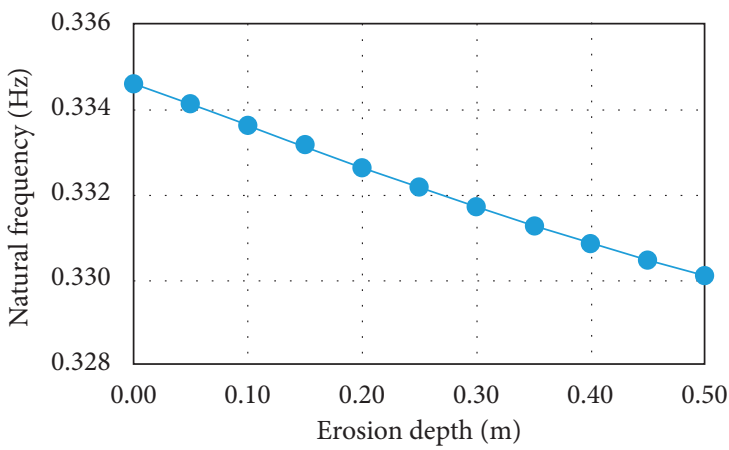

(d)

Figure 8: Dynamic characteristics due to the erosion depth. (a) 1st mode of the vertical vibration modes; (b) 2nd mode of the vertical vibration modes; (c) 1st mode of the transversal vibration modes; (d) 2nd mode of the transversal vibration modes.

It can be seen from Figure 9 that the 2nd mode of the vertical vibration modes changed obviously due to the erosion depth and the 1st mode of the vertical vibration modes was almost not influenced by the erosion depth. In addition, the 1st mode and the 2nd mode of the transversal vibration modes changed almost synchronously. Although the 2 nd mode of the vertical vibration modes was more sensitive, its natural frequency was so small, which is not easy to obtain on site. By comparing the 1st of vertical vibration modes with the 1st of transversal vibration modes, it can be found that the erosion depth had a more substantial influence on the transversal vibration.
In other words, the souring depth is more sensitive than the erosion depth and the 2nd vertical mode is most substantially influenced by scouring and erosion. Because of the small value of the natural frequency of the vertical vibration modes, the transversal vibration modes may be more convenient to obtain.

4.2. Vertical Dynamic Responses. This paper will discuss the results in terms of the three aspects of the vehicle speed, scouring depth, and erosion depth to determine the main factors that affect the dynamic responses of the bridge. In addition, by comparing the dynamic responses of section 


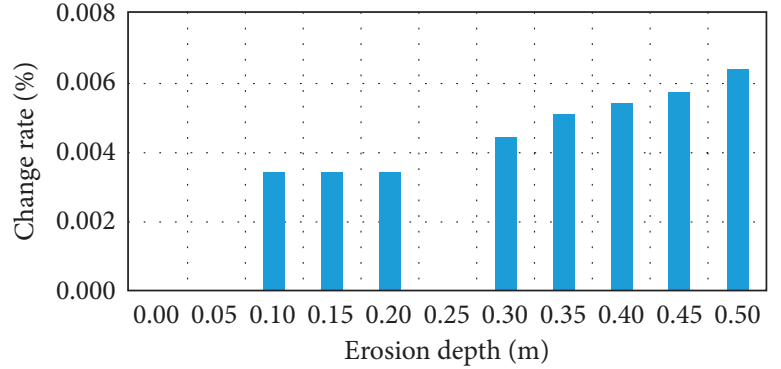

(a)

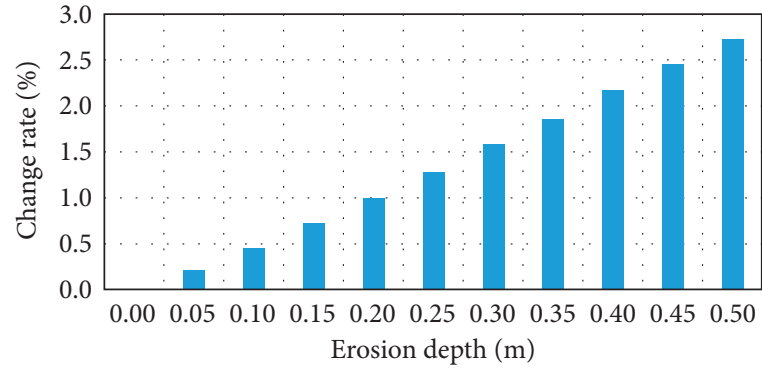

(c)

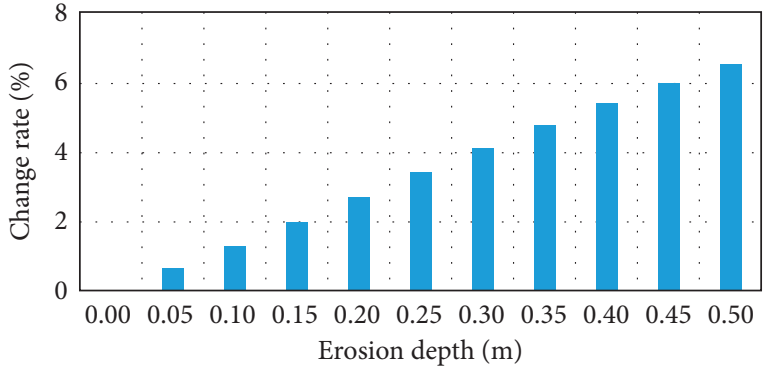

(b)

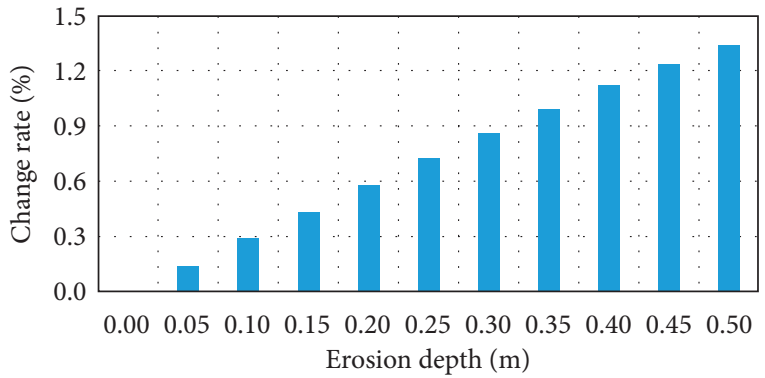

(d)

Figure 9: Change rate of the dynamic characteristics due to the erosion depth. (a) 1st mode of the vertical vibration modes; (b) 2nd mode of the vertical vibration modes; (c) 1st mode of the transversal vibration modes; (d) 2nd mode of the transversal vibration modes.

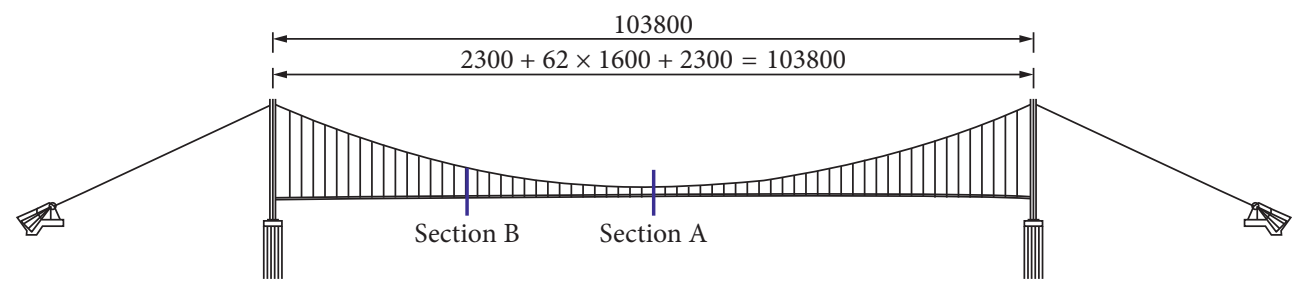

FIGURE 10: Selected sections.

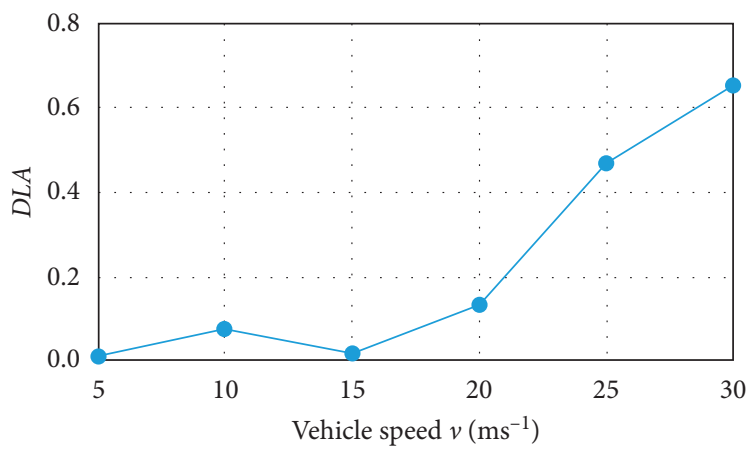

(a)

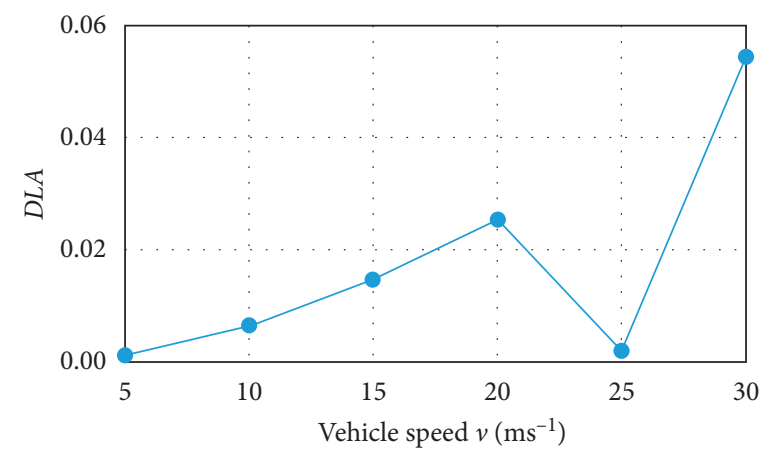

(b)

Figure 11: Dynamic load allowance of different vehicle speeds. (a) Vertical. (b) Transverse.

A and section B (section A is the middle of the span's section and section B is the quarter distance of the span's section, as shown in Figure 10), the position and index of scouring detection can be determined.

First, we selected the medium deck roughness, changed the vehicle speed from $5 \mathrm{~m} / \mathrm{s}$ to $30 \mathrm{~m} / \mathrm{s}$ in increments of $5 \mathrm{~m} /$ $\mathrm{s}$, used the maximum dynamic displacement in section $\mathrm{A}$ as the index to judge the most sensitive speed of the bridge, and established the ANSYS finite element analysis model. The calculation and analysis results are shown in Figure 11.

From Figure 11, it can be seen that the maximum dynamic vertical displacement and the maximum dynamic transversal displacement in section A occurred when the speeds were $30 \mathrm{~m} / \mathrm{s}$ and $20 \mathrm{~m} / \mathrm{s}$. The dynamic response is 


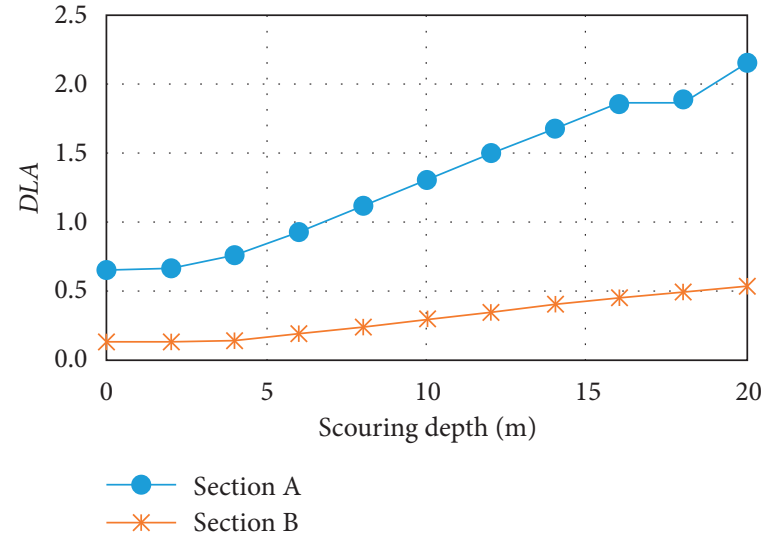

(a)

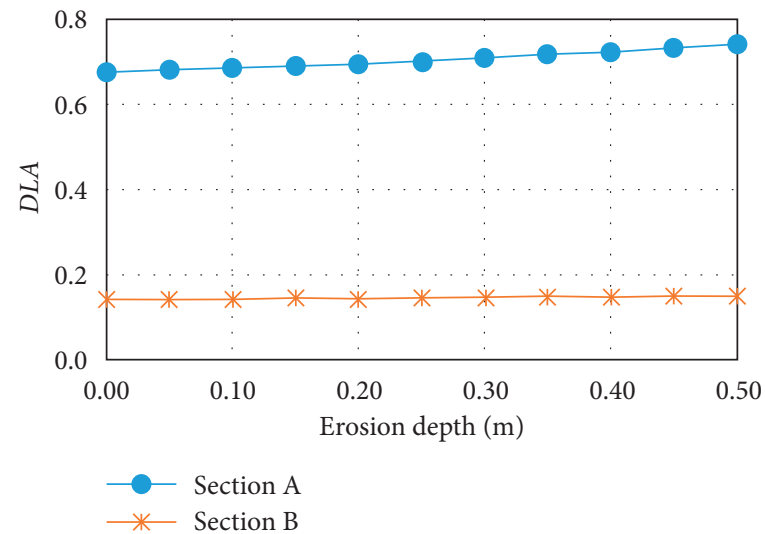

(c)

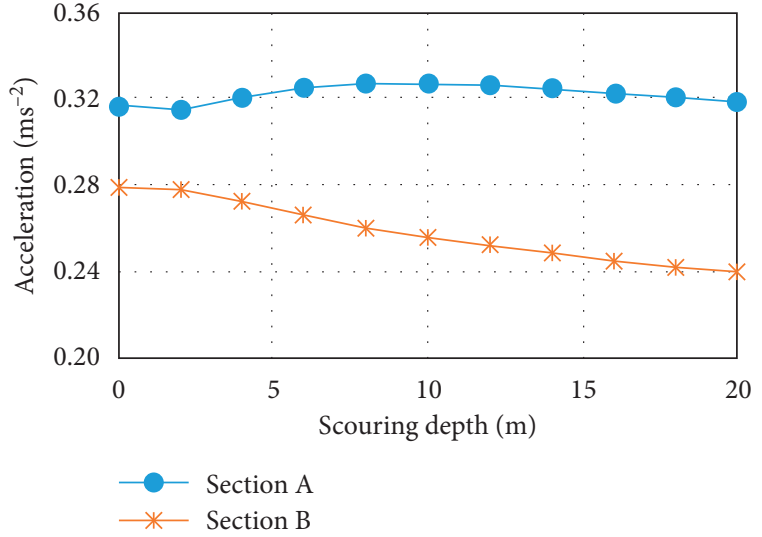

(b)

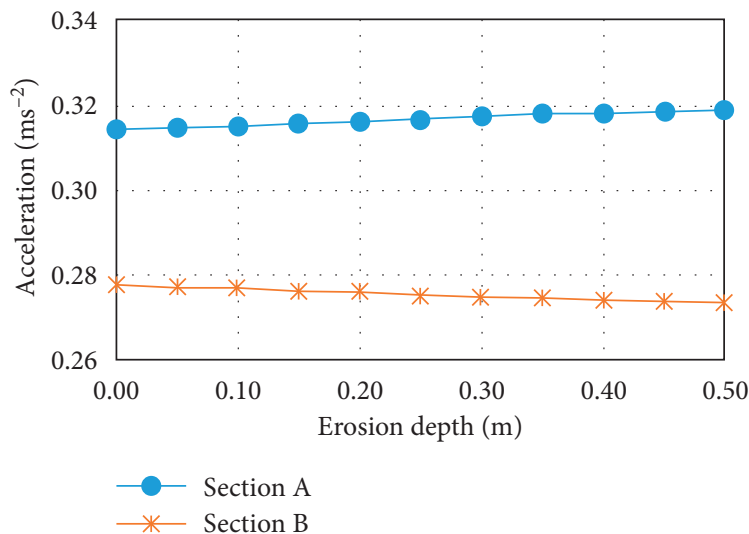

(d)

FIgURE 12: Vertical dynamic responses.

TABle 5: Vertical dynamic responses.

\begin{tabular}{|c|c|c|c|c|c|c|c|c|c|}
\hline \multirow[t]{2}{*}{ Scouring depth } & \multicolumn{2}{|c|}{$\begin{array}{c}\text { Dynamic load } \\
\text { allowance (DLA) }\end{array}$} & \multicolumn{2}{|c|}{ Acceleration } & \multirow[t]{2}{*}{ Erosion depth } & \multicolumn{2}{|c|}{$\begin{array}{c}\text { Dynamic load } \\
\text { allowance (DLA) }\end{array}$} & \multicolumn{2}{|c|}{ Acceleration } \\
\hline & Section A & Section B & Section A & Section B & & Section A & Section B & Section A & Section B \\
\hline 0 & 0.657 & 0.144 & 0.3164 & 0.2793 & 0.00 & 0.676 & 0.141 & 0.3146 & 0.2774 \\
\hline 2 & 0.671 & 0.141 & 0.3145 & 0.2778 & 0.05 & 0.680 & 0.141 & 0.3150 & 0.2770 \\
\hline 4 & 0.763 & 0.154 & 0.3202 & 0.2720 & 0.10 & 0.684 & 0.141 & 0.3154 & 0.2766 \\
\hline 6 & 0.927 & 0.194 & 0.3245 & 0.2660 & 0.15 & 0.690 & 0.142 & 0.3159 & 0.2762 \\
\hline 8 & 1.120 & 0.246 & 0.3265 & 0.2607 & 0.20 & 0.696 & 0.143 & 0.3164 & 0.2758 \\
\hline 10 & 1.316 & 0.301 & 0.3267 & 0.2560 & 0.25 & 0.702 & 0.143 & 0.3169 & 0.2753 \\
\hline 12 & 1.506 & 0.354 & 0.3259 & 0.2520 & 0.30 & 0.710 & 0.144 & 0.3174 & 0.2749 \\
\hline 14 & 1.686 & 0.404 & 0.3244 & 0.2485 & 0.35 & 0.716 & 0.146 & 0.3178 & 0.2744 \\
\hline 16 & 1.854 & 0.452 & 0.3226 & 0.2454 & 0.40 & 0.724 & 0.147 & 0.3183 & 0.2740 \\
\hline 18 & 1.892 & 0.498 & 0.3206 & 0.2427 & 0.45 & 0.730 & 0.148 & 0.3186 & 0.2736 \\
\hline 20 & 2.152 & 0.543 & 0.3186 & 0.2402 & 0.50 & 0.738 & 0.149 & 0.3190 & 0.2732 \\
\hline
\end{tabular}

influenced by the natural frequency of the bridge, the natural frequency of the vehicle, and the vehicle speed. Obviously, the natural frequencies of the bridge in the vertical direction and transversal direction are different because the two speeds are not the same. A speed of $30 \mathrm{~m} / \mathrm{s}$ is adopted.

In this paper, the maximum dynamic displacement and acceleration of the control section are selected as the dynamic response of the bridge and the dynamic load allowance is used as the index to judge the maximum dynamic displacement. They are used to compare the sensitivity of each control section for different dynamic responses and finally determine the position and index of scouring detection. The calculation results are shown in Figure 12 and Table 5. 


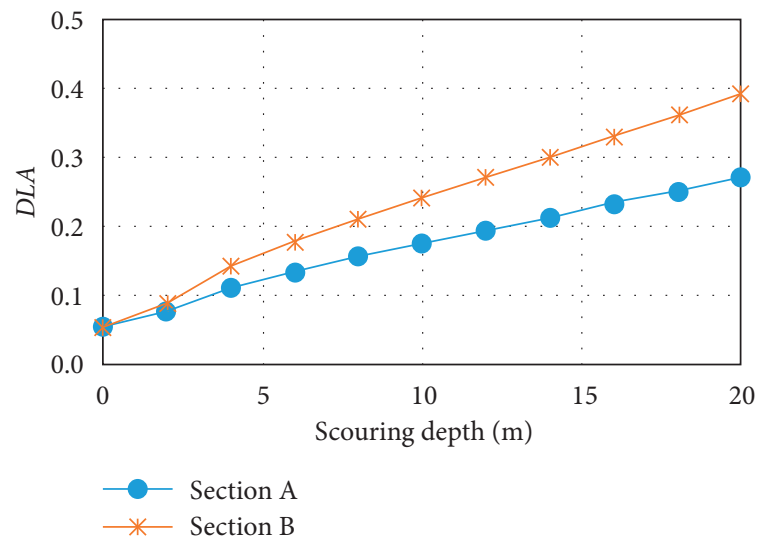

(a)

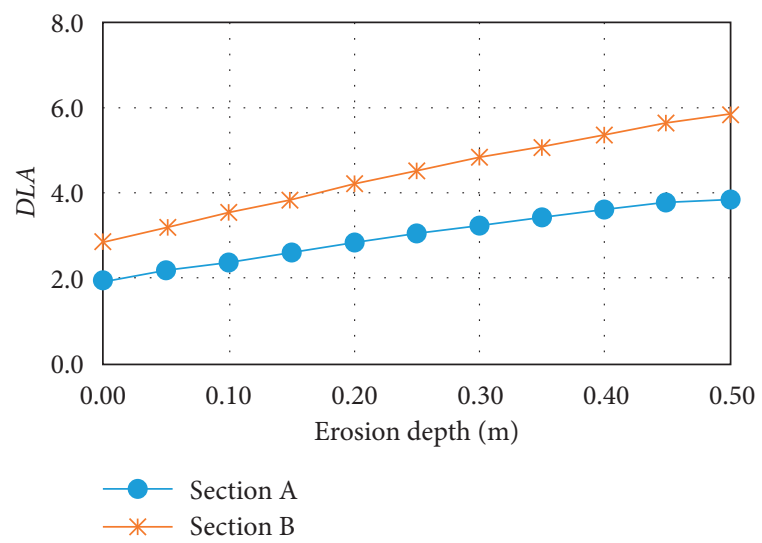

(c)

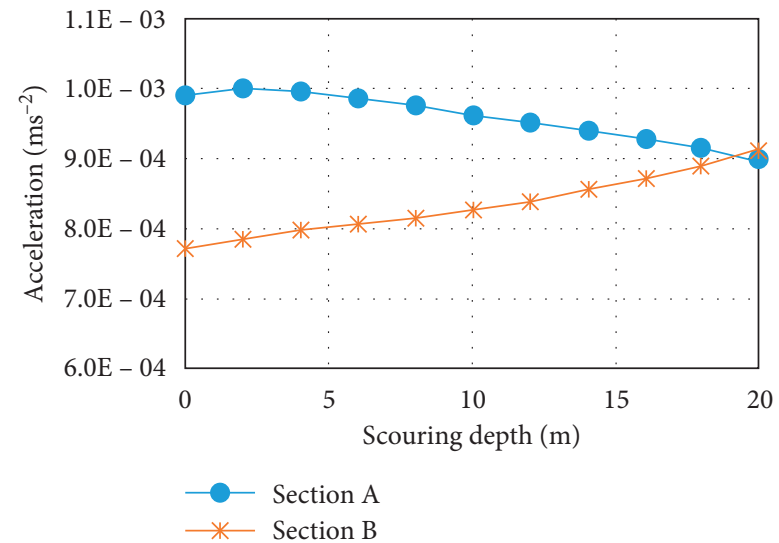

(b)

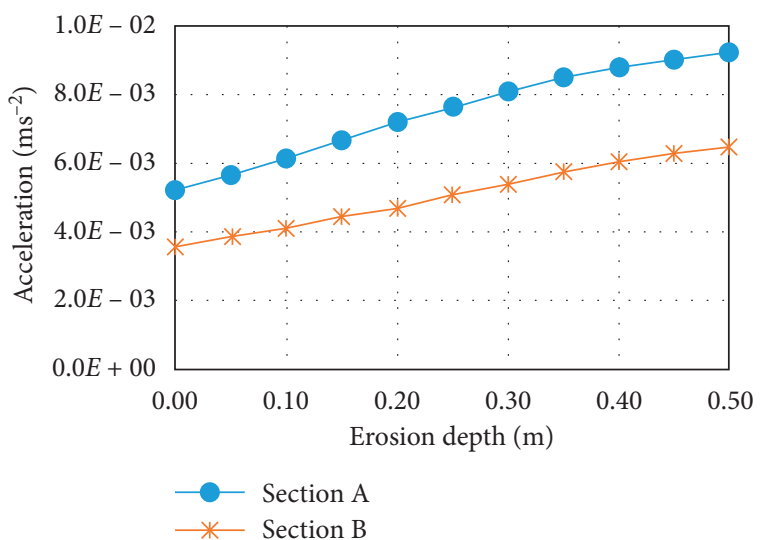

(d)

Figure 13: Transversal dynamic responses.

TABle 6: Transversal dynamic responses.

\begin{tabular}{|c|c|c|c|c|c|c|c|c|c|}
\hline \multirow[t]{2}{*}{ Scouring depth } & \multicolumn{2}{|c|}{$\begin{array}{c}\text { Dynamic load } \\
\text { allowance (DLA) }\end{array}$} & \multicolumn{2}{|c|}{ Acceleration } & \multirow[t]{2}{*}{ Erosion depth } & \multicolumn{2}{|c|}{$\begin{array}{c}\text { Dynamic load } \\
\text { allowance (DLA) }\end{array}$} & \multicolumn{2}{|c|}{ Acceleration } \\
\hline & Section A & Section B & Section A & Section B & & Section A & Section B & Section A & Section B \\
\hline 0 & 0.055 & 0.053 & $9.90 E-04$ & $7.70 E-04$ & 0.00 & 1.952 & 2.849 & $5.19 E-03$ & $3.53 E-03$ \\
\hline 2 & 0.079 & 0.090 & $9.98 E-04$ & $7.85 E-04$ & 0.05 & 2.165 & 3.173 & $5.63 E-03$ & $3.84 E-03$ \\
\hline 4 & 0.110 & 0.141 & $9.95 E-04$ & $7.99 E-04$ & 0.10 & 2.384 & 3.505 & $6.16 E-03$ & $4.14 E-03$ \\
\hline 6 & 0.135 & 0.178 & $9.85 E-04$ & $8.07 E-04$ & 0.15 & 2.604 & 3.839 & $6.69 E-03$ & $4.42 E-03$ \\
\hline 8 & 0.156 & 0.211 & $9.75 E-04$ & $8.17 E-04$ & 0.20 & 2.822 & 4.170 & $7.18 E-03$ & $4.68 E-03$ \\
\hline 10 & 0.175 & 0.241 & $9.63 E-04$ & $8.27 E-04$ & 0.25 & 3.036 & 4.495 & $7.65 E-03$ & $5.05 E-03$ \\
\hline 12 & 0.194 & 0.270 & $9.52 E-04$ & $8.39 E-04$ & 0.30 & 3.240 & 4.808 & $8.08 E-03$ & $5.41 E-03$ \\
\hline 14 & 0.213 & 0.300 & $9.41 E-04$ & $8.54 E-04$ & 0.35 & 3.433 & 5.104 & $8.46 E-03$ & $5.74 E-03$ \\
\hline 16 & 0.232 & 0.330 & $9.29 E-04$ & $8.72 E-04$ & 0.40 & 3.611 & 5.379 & $8.78 E-03$ & $6.03 E-03$ \\
\hline 18 & 0.252 & 0.359 & $9.15 E-04$ & $8.91 E-04$ & 0.45 & 0.730 & 0.148 & $9.04 E-03$ & $6.30 E-03$ \\
\hline 20 & 0.271 & 0.390 & $8.99 E-04$ & $9.13 E-04$ & 0.50 & 0.738 & 0.149 & $9.22 E-03$ & $6.48 E-03$ \\
\hline
\end{tabular}

From Table 5 and Figures 12(a) and 12(b), it can be seen that, with increasing scouring depth, the dynamic load allowances of section $A$ and section $B$ increase, while the change in the maximum vertical acceleration of section $A$ is insignificant and that of section B decreases linearly. From Figure 12(a), it can be seen that the vertical dynamic load allowance of section $\mathrm{A}$ is substantially greater than that of section B. From Figure 12(b), the change in section $\mathrm{B}$ is more obvious.

From Figures 12(c) and 12(d), it can be seen that, with the increase in the erosion depth, the dynamic load allowances of 
section $\mathrm{A}$ and section $\mathrm{B}$ increase continuously, but the change range in section $B$ is small and the vertical maximum acceleration change in section A and section B is not obvious.

4.3. Transversal Dynamic Responses. In this paper, the maximum dynamic displacement and acceleration of the control section are selected as the dynamic response of the bridge and the dynamic load allowance is used as the index to determine the maximum dynamic displacement. They are used to compare the sensitivity of each control section to different dynamic responses and finally determine the position and index of scouring detection. The calculation results are shown in Figure 13 and Table 6.

From Table 6 and Figures 13(a) and 13(b), it can be seen that, with the increase in the scouring depth, the dynamic load allowances of section A and section B increase; however, the maximum vertical accelerations of section $A$ and section $B$ are within $10-3 \mathrm{~m} / \mathrm{s}^{2}$, and the change can be ignored. From Figure 13(a), the change in the vertical dynamic load allowance of section $\mathrm{A}$ is substantially greater than that of section B.

From Figures 13(c) and 13(d), it can be seen that, with the increase in the erosion depth, the dynamic load allowances of section A and section B increase continuously; however, the maximum vertical accelerations of section $\mathrm{A}$ and section $B$ are within $0.5 \times 10-3 \mathrm{~m} / \mathrm{s}^{2}$, and the change can be ignored. Figure 13(c) shows that the dynamic load allowance of section B is slightly larger than that of section A.

\section{Conclusions}

The souring depth is more sensitive than the erosion depth, and the 2 nd vertical mode is most substantially influenced by scouring and erosion. Because of the small value of the natural frequency of the vertical vibration modes, the transversal vibration modes may be more convenient to obtain.

The impact of the scouring depth on the dynamic response of the bridge is mainly reflected in the dynamic load allowance. Regardless of the transverse and vertical directions, the quarter and midspan sections are all positively linearly related. Among them, the scouring depth has the greatest impact on the vertical impact coefficient of the midspan section, and the vertical dynamic load allowance of the midspan section should be selected to characterize the scouring depth. In contrast, the influence of the scouring depth on the acceleration is almost negligible.

The impact of the erosion depth on the dynamic response of the bridge is mainly reflected in the transversal direction, and both the dynamic load allowance and acceleration are positively related to the erosion depth. Among them, the erosion depth has the greatest impact on the transversal dynamic load allowance at the quarter location of the span's section, and the transversal dynamic load allowance of the quarter location of the span's section should be selected to characterize the scouring depth. In contrast, the influence of the vertical dynamic response is almost negligible.

\section{Data Availability}

The data used to support the findings of this study are included within the article.

\section{Conflicts of Interest}

The authors declare that there are no conflicts of interest regarding the publication of this paper.

\section{Acknowledgments}

This research was financially supported by the National Natural Science Foundation of China (Grant no. 51778194), the China Postdoctoral Science Foundation (Grant no. 2017M621282), and the Fundamental Research Funds for the Central Universities (Grant no. HIT. NSRIF. 2019056).

\section{References}

[1] M. A. Jian, S. U. N. Shouzeng, and Y. Qi, "Review on China's bridge engineering research: 2014," China Journal of Highway and Transport, vol. 27, no. 5, pp. 1-96, 2014.

[2] Q. F. Gao, Z. L. Dong, K. M. Cui, C. G. Liu, and Y. Liu, "Fatigue performance of profiled steel sheeting-concrete bridge decks subjected to vehicular loads," Engineering Structures, vol. 213, Article ID 110558, 2020.

[3] A. Elsaid and R. Seracino, "Rapid assessment of foundation scour using the dynamic features of bridge superstructure," Construction and Building Materials, vol. 50, pp. 42-49, 2014.

[4] S. Zhang and Y. Liu, "Damage detection of bridges monitored within one cluster based on the residual between the cumulative distribution functions of strain monitoring data," Structural Health Monitoring, vol. 19, no. 6, pp. 1764-1789, 2020.

[5] J. Guo and B. Jiang, "Research progress and key issues of bridge pile scour in recent 30 years," China Journal of Highway and Transport, vol. 33, no. 07, pp. 1-16, 2020.

[6] Q. Xiang, Y. Li, W. Kai et al., "Review of bridge foundation scour," Journal of Southwest Jiaotong University, vol. 54, no. 2, pp. 235-248, 2019.

[7] K. Wardhana and F. C. Hadipriono, "Analysis of recent bridge failures in the United States," Journal of Performance of Constructed Facilities, vol. 17, no. 3, pp. 144-150, 2003.

[8] P. F. Lagasse, Countermeasures to Protect Bridge Piers from scour, Transportation Research Board, Washington, DC, USA, 2007.

[9] Z. Zhang, X. Liu, Y. Zhang, M. Zhou, and J. Chen, "Time interval of multiple crossings of the wiener process and a fixed threshold in engineering," Mechanical Systems and Signal Processing, vol. 135, Article ID 106389, 2020.

[10] Y. Li, C. Fang, F. Qiu et al., "Wave current force action and foundation scour of marine bridges," Chinese Journal of Engineering Science, vol. 21, no. 3, pp. 18-24, 2019.

[11] S. Foti and D. Sabia, "Influence of foundation scour on the dynamic response of an existing bridge," Journal of Bridge Engineering, vol. 16, no. 2, pp. 295-304, 2011.

[12] H.-Y. Jia, D.-Y. Zhang, S.-X. Zheng, W.-C. Xie, and M. D. Pandey, "Local site effects on a high-pier railway bridge under tridirectional spatial excitations: nonstationary stochastic analysis," Soil Dynamics and Earthquake Engineering, vol. 52, pp. 55-69, 2013. 
[13] L. J. Prendergast, D. Hester, and K. Gavin, "Development of a vehicle-bridge-soil dynamic interaction model for scour damage modelling," Shock and Vibration, vol. 2016, Article ID 7871089, 15 pages, 2016.

[14] F.-Y. Liang, C. Wang, C.-Y. Jia, and Y Wang, "Model test on the influence of scour depth on modal parameters of simply supported bridge," Journal of Vibration and Shock, vol. 35, no. 14, pp. 145-150, 2016.

[15] X. Wen, Z. Chen, and J. Ye, "Condition assessment of bridge scour by tracing dynamic performance of bridges," China Journal of Highway and Transport, vol. 30, no. 5, pp. 89-96, 2017.

[16] F. N. Catbas, M. Gul, and J. L. Burkett, "Conceptual damagesensitive features for structural health monitoring: laboratory and field demonstrations," Mechanical Systems and Signal Processing, vol. 22, no. 7, pp. 1650-1669, 2008.

[17] X. Zhang, W. Yao, Y. Liu, and B. Chen, "Research on identification method of scour depth for bridge based on ERA and SVM," Shock and Vibration, vol. 2015, Article ID 346820, 2015.

[18] B. A. Vijayasree, T. I. Eldho, B. S. Mazumder, and N. Ahmad, "Influence of bridge pier shape on flow field and scour geometry," International Journal of River Basin Management, vol. 17, no. 1, pp. 109-129, 2019.

[19] F. Scozzese, L. Ragni, E. Tubaldi, and F. Gara, "Modal properties variation and collapse assessment of masonry arch bridges under scour action," Engineering Structures, vol. 199, Article ID 109665, 2019.

[20] Q. F. Gao, K. M. Cui, J. Li, B. Q. Guo, and Y. Liu, "Optimal layout of sensors in large-span cable-stayed bridges subjected to moving vehicular loads," International Journal of Distributed Sensor Network, vol. 16, no. 1, Article ID 1550147719899376, 2020.

[21] Q. Gao, Z.-L. Wang, J. Li, C Chen, and H.-Y. Jia, "Dynamic load allowance in different positions of the multi-span girder bridge with variable cross-section," Journal of Vibroengineering, vol. 17, no. 4, pp. 2025-2039, 2015. 